\title{
Recycling of Polyethylene Terephthalate Wastes in Production of Hollow Sandcrete Blocks for Sustainable Construction
}

\author{
O.M Olofinnade ${ }^{1, a^{*}}$ I.E.E Davies ${ }^{1, b}$ and I.W Egwuonwu ${ }^{1, c}$ \\ ${ }^{1}$ Department of Civil Engineering, Covenant University, PMB 1023, Ota, Nigeria \\ a*rotimi.olofinnade@covenantuniversity.edu.ng, bdavies.iyinoluwa@lmu.edu.ng, \\ cifeoma.egwuonwu@stu.cu.edu.ng
}

Keywords: Waste plastic, Polyethylene terephthalate (PET), Compressive strength, Density, Water absorption, Eco-friendly production

\begin{abstract}
This study investigates the suitability of crushed polyethylene terephthalate (PET) waste, which is a non-biodegradable generated waste as a substitute material for natural sand in the production of hollow sandcrete blocks for sustainable infrastructure. The physical properties of the natural sand and crushed PET aggregate materials used in the batching mixtures which include; specific gravity, water absorption, bulk density and particle size distribution were determined. While the mechanical properties; density, compressive strength, and the water absorption of the produced hollow sandcrete block samples using the granulated PET aggregate as a replacement for natural sand at 5\%,10\%,30\% and 50\% were studied. Results showed that the PET aggregates exhibit lower physical properties compare to natural sand. The addition of the finely granulated PET aggregates as a partial substitute for natural sand gradually reduced the density of the hollow sandcrete blocks as the replacement increases in the mix. However, the water absorption tendency of the sandcrete blocks reduces as the percentage dosages of PET aggregate increases. A similar reduction trend was noticed in the compressive strength of the produced hollow sandcrete blocks. The results showed a strength reduction from $2.564 \mathrm{~N} / \mathrm{mm}^{2}$ to $1.140 \mathrm{~N} / \mathrm{mm}^{2}$ for sandcrete mixes containing $5 \%$ and $50 \%$ PET, respectively, and $2.991 \mathrm{~N} / \mathrm{mm}^{2}$ to $1.510 \mathrm{~N} / \mathrm{mm}^{2}$ for sandcrete mixes containing $5 \%$ and $50 \%$ PET, respectively as the percentage substitution of sand with PET increases for 7 and 28 days curing age. The obtained results indicate the possibility of using granulated PET aggregate at 5\% sand replacement in production of hollow sandcrete blocks of comparable strength to conventional sandcrete blocks. This will help to promote green production for sustainable infrastructure and reducing the menace of plastic pollution in line with the UN Sustainable Development Goals.
\end{abstract}

\section{Introduction}

Annually, global waste generation, both organic and inorganic materials have been on the increase due to the rise in world population and urbanization [1]. Shekdar [2] mentioned that besides the population growth and urbanization, waste generation could also be associated with the economic status of a nation.

In recent times a vast quantity of generated trash is the result of consuming products, which become wastes after use. These generated wastes are most times non-segregated, especially in developing nations, which has poor waste handling facilities and therefore, may be dangerous or nondangerous to public health [1]. Substantial parts of this generated trash contain non-biodegradable plastics, of various types that are mostly indiscriminately disposed on unauthorized open dumpsites and drainages, causing great harm to the marine life, environment and public health [3]. Karak et al. [1] emphasized that poorly managed waste impact on the quality of life, environment and esthetic.

Polyethylene terephthalate (PET) is rated as one of the most produced plastics and are used globally in the packaging of different products such as water, beverage, foods, soft drinks and other consumer's goods $[4,5]$. The consumption of PET used in the bottling of drinks was reported to be about 10 million tons annually and is estimated to be rising at about $15 \%$ annually [4]. The PET plastics are widely used throughout much of the developed and developing nations [6]. 